\title{
História dos conceitos: problemas e desafios para uma releitura da modernidade ibérica'
}

Conceptual History: Questions

and Challenges Concerning

a Reappraisal of the Iberian

Modernity

Valdei Lopes de Araujo

Professor no Departamento de

História da Universidade Federal de

Ouro Preto

\section{Resumo}

Este artigo discute aspectos metodológicos da história dos conceitos a partir da leitura do texto "Historia, Experiência y Modernidad em lberoamerica, 1750-1850", de Guillermo Zermeño. São analisados conceitos como modernidade e história, particularmente para o contexto iberoamericano entre 1750 e 1850. Abordam-se igualmente aspectos gerais das relações entre dinâmica conceitual e história político-social.

\begin{abstract}
From the reading of Guillermo Zermeño "History, Experience and Modernity in Portuguese and Spanish America, 1750-1850", this article discusses some methodological aspects of conceptual history. The concepts of history and modernity are analyzed for the period between 1750 and 1850. The article also focuses on the relations between conceptual and socio-political history.
\end{abstract}

\section{Palavras-chave}

história das idéias, Independência, vocabulário político

\section{Keywords}

history of ideas, Independence, political vocabulary
Este texto é devedor do excelente ambiente intelectual que tenho o privilégio de compartiIhar no âmbito do Projeto Temático Formação do Estado e da Nação: Brasil c.1780-1850, coordenado pelo professor István Jancsó. 
0 próprio Zermeño tem sistematicamente contribuido para o avanço dessa investigação, como pode ser constato em ZERMEÑO, Guillermo. La cultura moderna de La historia: uma aproximación teórica e Historiográfica. México: El Colegio de México, Centro de Estudios Históricos, 2004. Em particular a primeira parte, dedicada à relação entre história e modernidade.
Antes mesmo do Giro Lingüístico redefinir as agendas de pesquisa nas Humanidades, a História dos Conceitos (Begriffsgeschichte) já havia estabelecido um programa de investigação com soluções teórico-metodológicas para o tratamento do texto e da linguagem como fenômenos históricos. É certo que as mesmas inquietações e fontes dos autores que depois seriam identificados com o Giro Lingüístico atuavam no projeto da Begriffsgeschichte. 0 texto "Historia, Experiência y Modernidad em Iberoamerica", de Guillermo Zermeño Padilla, ao mesmo tempo em que apresenta um preciso panorama dos resultados parciais desse campo de investigação, propõe caminhos para a releitura da modernidade lbérica. ${ }^{2}$ Nossa intenção nesse artigo é recolocar, a partir do debate com o texto de Zermeño, alguns problemas e desafios teórico-metodológicos para uma reescrita da história da modernidade no Brasil a partir do diálogo entre a história político-social e a história dos conceitos.

\section{I. $\mathbf{0}$ que é um conceito histórico?}

Uma das marcas do modernismo epistemológico na historiografia foi a crescente centralidade do sujeito na produção do conhecimento. Invertiase assim apenas o primado do objeto, que caracterizou o cientificismo de fins do século XIX. Uma das conseqüências dessa fixação na dupla sujeito/ objeto foi a simplificação da linguagem como campo de estudos da historiografia. Ou a linguagem era mero veículo de comunicação de um mundo de objetos autônomos, ou o exercício livre de uma subjetividade individual ou coletiva. 0 que a história dos conceitos trouxe de novo foi considerar a linguagem como um fenômeno irredutivel às demais dimensão do real. Dito de outra forma, a linguagem é investida de uma autonomia relativa passivel de tratamento teórico-metodológico específico.

Entender a linguagem como constituída e constituinte da realidade não seria suficiente para prover uma agenda de investigação historiográfica. No interior da linguagem, os conceitos são os objetos de maior efetividade histórica, eles fazem a mediação entre experiência e expectativa, individual e social, o lingüístico e o extralingüistico. Nos conceitos, a linguagem opera como força histórica, consolidando ou desfazendo configurações do mundo da vida. Um conceito histórico é sempre resultado da precipitação de um conjunto experiencial, surge no mundo tão materialmente quanto qualquer coisa, não como mera representação mental. Aqui não importa a divisão metafísica entre o material e o imaterial. Um conceito histórico é tão material quanto um processo produtivo, por isso não pode ser tratado apenas como representação. Em sua existência, um conceito realiza-se por atos de fala, não é uma idéia na mente de um autor, mas um conjunto rastreável de performances discursivas capaz de deixar vestígios concretos para a investigação historiográfica.

Um conceito histórico não é uma invenção livre da subjetividade do historiador, mas uma totalidade semântica produzida na contingência histórica. Portanto, cabe ao pesquisador recuperar essas dimensões disponiveis nos vestígios e na própria continuidade histórico-cultural. Recuperar os significados em disputa dos conceitos históricos exige uma reconstrução complexa de seus contextos de enunciação, tanto em sua dimensão sincrônica, quanto diacrônica. Essa exigência materializa-se em um novo olhar sobre os textos canônicos lidos e relidos pela história intelectual e pela história das idéias. Obras até então negligenciadas de grandes autores, ou mesmo autores esquecidos pelas visões hegemônicas, são recuperados como momentos fundamentais para a compreensão do contexto discursivo. Os jornais e panfletos, dicionários e vocabulários, assim como os debates 
3

Para algumas observações fundamentais sobre a noção de contexto, ver SEBASTIÁN, Javier Fernández. "Intellectual History, Liberty and Republicanism: An Interview with Quentin Skinner". Contributions to the History of Concepts, 3 (2007), p.103-123.

4

Esse debate tem sido consistentemente travado pelos "contextualistas" ingleses, como amostra, remeto a POCOCK, John G. A.. O Estado da Arte. In ____. Linguagens do Ideário Político. São Paulo: Edusp, 2003. p. 23-62 e SKINNER, Quentin. Interpretation and the understanding of speech action. In _____. Visions of Politics: regarding method. Cambridge: Cambridge University Press, 2006. p. 103-127. parlamentares tornaram-se matéria-prima fundamental para a reconstrução dos contextos discursivos. ${ }^{3}$

A velha categoria da influência, cara à tradicional história das idéias, cede lugar para formas de transplantação e tradução de uma mesma experiência histórica em diversos cenários nacionais, regionais e locais. A figura solar do autor/sujeito com sua intencionalidade é relativizada frente à nova concepção do texto enquanto acontecimento e pragmática, bem como pela ênfase nos contextos e jogos de linguagem que têm como território não a mente autoral, mas os veículos de circulação e espaços de sociabilidade. ${ }^{4}$ Da mesma forma que o sujeito-autor, também o sujeito-nação tem sua capacidade explicativa relativizada quando nos damos conta das múltiplas territorialidades relacionais concretamente produzidas em um determinado tempo/espaço. Não é possível falar de conceitos nacionais enquanto algo isolado das teias formadas na circulação entre o local, o regional e o global.

A leitura dos textos históricos deixa de ser apenas a busca de uma romântica empatia com o autor, ou ainda a coleta de informações não intencionais como matéria prima da história social, das representações coletivas ou da crítica das ideologias. Como testemunho histórico efetivo de mundos da vida não mais inteiramente disponiveis, os textos podem nos oferecer um acesso privilegiado às formas pelas quais determinada sociedade experimentou, concebeu e prefigurou a realidade. Como demonstrou Reinhart Koselleck, os conceitos são sintomas e produtores de transformações sociais, portanto, mesmo que possamos e devamos articulá-los com as demais dimensões constitutivas da realidade, não podemos nos esquecer de seus movimentos autônomos, capazes de produzir novas e imprevistas configurações.

Assim, um conceito não é uma idéia ou uma palavra, não é uma representação, nem parte de um imaginário coletivo. Os conceitos históricos são fenômenos reais que atuam em qualquer sociedade humana, instrumentos cognitivos produzidos na existência concreta. Os sujeitos históricos possuem graus de consciência variados e sempre polêmicos acerca dos conceitos. A definição dos conceitos históricos fundamentais é sempre objeto de disputa social, não cabendo ao historiador estabelecê-los normativamente como deve fazê-lo com suas categorias de análise, mas descrevêlos em sua amplitude variável e narrá-los em sua dinâmica concreta.

Através do recurso a um corpus documental representativo é possivel datar o momento em que um novo conceito nasce, ou em que novos significados aderem a velhas palavras. Embora um conceito quase sempre esteja associado a um vocábulo, ele não se reduz a uma palavra. Um conceito é uma forma específica de lidar com campos da realidade, ao mesmo tempo em que os organiza, tornando-os instrumentais, ele nos faz cegos para fenômenos desses mesmos campos que extravasam ou contradizem a estrutura lógico/ semântica que o conceito impõe. Por isso, uma mudança conceitual envolve, na maioria das vezes, a abertura de uma nova experiência do real.

\section{As condições de emergência da História dos Conceitos}

Como um produto intelectual do segundo pós-guerra, a História dos Conceitos surgiu em um cenário de profunda revisão do projeto moderno. Como destaca Zermeño, a concepção normativa de modernidade, forjada na segunda metade do século XVIII, perdurou, não sem profundos questionamentos, até a década de 50 do século XX. Os grandes-relatos de uma modernização progressiva em curso linear na história do Ocidente esgotavam-se tanto do ponto de vista teórico, quanto como conseqüência 
A emergência de um novo tipo de história da historiografia foi sucessivamente apontada como sintoma de profundas transformações sócio-culturais em NORA, Pierre. Entre Memória e História: a problemática dos lugares. Projeto História. São Paulo: PUC-SP, Nº 10, 1993; GUMBRECHT, Hans Ulrich. Depois de aprender com a história In ____. Em 1926: vivendo no limite do tempo. Rio de Janeiro: Record, 1999. p. 459-485; e HARTOG, François. Regimes d'Historicité. Présentisme et expériences du temps.Paris: Éditions du Seuil, 2003. p. 138ss.

Cf. KOSELLECK, Reinhart. História dos conceitos e história social In ____. Futuro pasado: contribuição à semántica dos tempos históricos. Rio de Janeiro: Contraponto/Puc-Rio, 2006. p. 97-118.

A critica a tais dualismos tem sido feita programaticamente por Richard Rorty desde o seu clássico "A Filosofia e o Espelho da Natureza", alguns dos argumentos centrais podem ser encontrados no ensaio "Fisicalismo não-redutivo" In RORTY, Richard. Objetivismo, relativismo e verdade: escritos filosóficos I. Rio de Janeiro: Relumé-Dumará, 1997. p. 157-172. das investigações que revelavam uma nova complexidade para a chamada história moderna, em particular para o período entre os séculos XVIII e XIX.

Um conjunto de categorias, que na grande narrativa da modernização possuía valor normativo, passou a compor a lista de objetos de investigação da Begriffsgeschichte: povo, história, civilização, razão, revolução, democracia e, sobretudo, o próprio conceito de modernidade. Não se tratava de buscar uma definição perfeita do termo que pudesse explicar as distintas modernizações, mas de tomar distância e enfrentar o moderno não apenas como nosso contemporâneo, mas em suas diversas e algumas vezes exóticas figurações. Assim, podemos afirmar que a crise de nossa identidade de época foi uma das condições históricas para tornar a modernidade objeto de indagação historiográfica.

A compreensão normativa da modernidade esteve sempre como fundamento da própria historiografia desde o século XIX, com a historicização do moderno, a historiografia também receberia nova perspectiva. Não se deve estranhar, portanto, que no projeto da Begriffsgeschichte os conceitos de modernidade e história tenham recebido tratamento destacado. Desde então, e por diversas frentes independentes da história dos conceitos, nossa compreensão da história moderna e da história da historiografia transformou-se profundamente. ${ }^{5}$

\section{Linguagem, autonomia e relativismo}

Essa nova dignidade da linguagem para o ofício do historiador deveria naturalmente nos fazer refletir sobre as relações entre o lingüistico e o extralingüistico. Nas últimas décadas posições variadas manifestaram-se, desde a reafirmação da linguagem como mera representação ou epifenômeno de estruturas mais fundamentais, até, no outro extremo, a afirmação de uma realidade concebida como pura linguagem. Entre o determinismo e o relativismo muitas outras soluções foram apresentadas. Em seu texto "História social e história dos conceitos", Koselleck enfrentou o problema diretamente. Mesmo afirmando a autonomia da História dos Conceitos e a centralidade da hermenêutica, deixou evidente que o historiador deve trabalhar com uma concepção de real no qual o lingüístico e o extralingüistico estão em constante tensão. ${ }^{6}$

Nos diversos modernismos epistemológicos somos levados a escolher entre uma realidade puro objeto ou puro sujeito. A partir da fenomenologia heideggeriana aprendemos a pensar o real como uma relação tensa entre a linguagem e as coisas. 0 sujeito é deslocado de sua posição solar - como produtor da realidade - e visto como integralmente inserido em um mundo que lhe é anterior. Ao dizer integralmente inserido refiro-me à falência do conceito de mente como algo pertencente a um plano não material e, portanto, à própria caducidade de uma oposição maniqueísta entre o material e o mental ou simbólico. ${ }^{7}$

Polemizando com Hans-Georg Gadamer, Koselleck sustentou o não esgotamento da historiografia aos procedimentos hermenêuticos. Sabemos que Martin Heidegger fundamentou a centralidade do sentido e da interpretação em categorias ligadas à finitude da existência humana. Como um ser consciente de sua existência finita, o homem conta com uma direcionalidade ausente nos demais seres. Sem negar a centralidade da finitude, Koselleck ressaltou a existência de muitas outras categorias fundamentais para que toda e qualquer história possa acontecer, muitas delas, como salienta Zermeño, não exclusivamente humanas, como amigo/inimigo, dentro/ 
Cf. KOSELLECK, Reinhart \& GADAMER, HansGeorg. Historia y Hermenéutica: la diversidad de las lenguas y la comprensión del mundo. Barcelona: Ediciones Paidós, 1997. p. 85.
10

Cf. SEBASTIÁN, Javiér Fernández \& FUENTES, Juan Francisco. Conceptual History, Memory, and Identity: An Interview with Reinhart Koselleck. Contributions to the History of Concepts, V. 2, N. 1, 2006. p. 99-127. fora, acima/abaixo, pai/filho, etc. ${ }^{8}$ Em um mesmo movimento, fica clara a exigência tanto de uma teoria da história capaz de desvendar e formular essas categorias transcendentais, bem como de disciplinas capazes de operar métodos analítico-formais e, portanto, não necessariamente hermenêuticos, para o conhecimento dessas realidades mudas. Preservar esse espaço é essencial para a fundamentação autônoma de uma história social estrutural e de uma teoria da história com prerrogativas próprias ao lado de uma história dos conceitos. Para isso devemos ser capazes de afirmar um real independente da linguagem e da subjetividade transcendental. Como salienta Heidegger, a historicidade do mundo não é uma doação do sujeito ao real, mas uma derivação do modo como a realidade acontece.

$\mathrm{Na}$ tentativa de diferenciar o status do texto para o historiador, em contraposição com os usos de juristas ou teólogos, Koselleck conclui:

\footnotetext{
El historiador procede de otro modo: se sirve básicamente de los textos sólo como testimonios para averiguar a partir de ellos una realidad existente allende los textos. Por consiguiente, tematiza, más que todos los otros exégetas de textos, un estado de cosas que en cualquier caso es extra textual, aun cuando él constituya su realidad sólo con medios lingüisticos. ${ }^{9}$
}

Certamente a autonomia da história dos conceitos não se vê ameaçada com isso, um conceito indicia mais que uma dimensão lingüistica, ele é sempre uma posição provisória entre o lingüístico e o extralingüístico. Talvez aqui pudéssemos clarear melhor a questão a partir da dimensão performativa da linguagem, ou seja, entender um conceito em sua pragmática como algo similar a um ato de fala. Por isso, concordaria apenas parcialmente com o corolário de Zermeño: "[...] sólo por medio de la observación y el análisis del lenguaje es posible acceder al espacio de experiencia propio de cada época". Acredito que ao lado desse trabalho com a linguagem, os métodos não hermenêuticos da história social e da teoria da história têm seu lugar, mesmo que esteja de acordo com Zermeño quanto à centralidade e primado da história dos conceitos no enfrentamento dos fenômenos significativos.

\section{Comparando conceitos: tradição e mundo ibérico}

No que se refere aos problemas da aplicação da perspectiva comparada na história dos conceitos, considero fundamental o destaque dado por Zermeño à existência de categorias meta-históricas como chave heurística para qualquer comparação, mas me pergunto se mantê-la apenas nesse nível não seria limitar por demais as possibilidades analíticas. Em entrevista, Koselleck chamou atenção para as dificuldades do projeto comparativo ${ }^{10}$, mas também para as possibilidades que o mundo ibérico abriria, tendo em vista que contamos com uma base cultural muito mais homogênea, a partir da qual se poderia verificar a dispersão das diferentes tradições nacionais para a mesma experiência do tempo. Ou seja, para a mesma sensação de aceleração poderiamos mapear distintas soluções históricas.

Essa ênfase em um legado de experiências comuns está relacionada com a concepção hermenêutica de tradição: como compreender uma experiência histórica da qual estamos excluídos? Como parte significativa do trabalho com os conceitos pressupõe certa continuidade históricocultural, a observação de Koselleck sobre o mundo ibérico poderia nos servir também de orientação teórica. Ou seja, a pressuposição de uma continuidade histórico-cultural como condição para uma história comparada 
11

Cf. KOSELLECK, Reinhart. Historia. Madrid:

Editorial Trotta, 2004, passim. dos conceitos. Por isso, quando Zermeño afirma que "[...] la posibilidad de comparación está dada menos por la información documental que por las categorias a priori utilizadas", corre-se o risco tornar a comparação por demais abstrata. Além das categorias a priori que podem ser produzidas por uma "teoria da história", também as categorias historiográficas, não apriorísticas - podemos chamá-las em alguns casos conceitos históricos vigentes -, podem servir de parâmetro comparativo desde que metodologicamente controladas. Por exemplo, modernidade enquanto uma categoria historiográfica definida como um tipo específico de relação entre experiência e expectativa pode servir de base para um projeto de comparação das várias experiências de modernidade vivenciadas pelo mundo Ibérico.

Empreender um projeto comparativo não meramente formal passaria necessariamente pela análise das relações históricas concretas estabelecidas por estas sociedades. Os conceitos e as experiências não estão limitados por fronteiras geográficas, mas são certamente condicionados por suas circunstâncias. Apenas o conhecimento efetivo da situação poderia definir os contextos relevantes para a compreensão de uma dinâmica conceitual comparada. Sabemos, por exemplo, que para um tipo específico de república das letras a literatura clássica romana é um contexto mais relevante do que a língua vernácula nacional. Aqui o próximo e o distante devem ser medidos com critérios de uma geografia/cronologia das formas de circulação e produção da experiência.

\section{Sobre a periodização da modernidade Iberoamericana}

A cronologia para a dinâmica do conceito de história no mundo ibérico proposta por Zermeño está dividida em três etapas: a primeira marcada pela predominância de uma concepção clássico-retórica de história; a segunda pela assimilação do conceito às histórias nacionais em seu processo de emancipação, definido ainda pela incerteza quanto ao resultado das grandes transformações político-sociais iniciadas, e, por fim, uma terceira etapa definida pela normalização da experiência em grandes narrativas e filosofias da história aplicadas à conjuntura das novas nações. Em linhas gerais, essa cronologia confirma o recorte proposto por Koselleck para o caso germânico. Enquanto a primeira e terceira etapas surgem bem definidas, pois representam, grosso modo, o velho e o novo mundo conceitual, parece haver certa dificuldade na definição da segunda etapa. Como caracterizá-la? É um momento de crise e transição? Essa questão não parece claramente resolvida nem mesmo nos trabalhos de Koselleck, pois quando definiu o Sattelzeit entre 1750 e 1850 ele não traçou, nem mesmo para o conceito de história, qualquer periodização intermediária, como procuramos fazer para o caso ibérico.

No verbete história do Dicionário de Conceitos Fundamentais ${ }^{11}$ podemos mapear a "evolução" de certas conquistas provisórias ou parciais, mas a impressão geral é a de que a grande "transição" entre o antigo e o moderno só estaria encerrada por volta de 1850. Os especialistas parecem indecisos quando se defrontam com as continuidades que surgem nesse recorte. Afinal, como caracterizar essa passagem para o mundo moderno? Não me parece acidental o fato de Koselleck ter evitado categorias como "regime de historicidade", ou mesmo "campos discursivos", que pressuporiam a capacidade de traçar uma linha muito nítida entre duas épocas. 0 conceito de regime serviu, por exemplo, para estabilizar a imagem que os franceses produziram sobre sua própria modernidade a partir de 1850, 
12

Cf. GUMBRECHT, Hans Ulrich. Cascatas de modernidade In ____. Modernização dos sentidos. São Paulo: Ed. 34, 1998. p. 9-32.
13

Questão fartamente documentada por GUIMARÃES, Lúcia Maria Paschoal. Debaixo da imediata proteção de Sua Majestade Imperial: o Instituto Histórico e Geográfico Brasileiro (1838-1889). Revista do Instituto Histórico e Geográfico Brasileiro, Rio de Janeiro: 156(388), jul./set. 1995. p. 513 e ss. dividindo os séculos entre Antigo e Novo Regime. Esse mesmo tipo de dificuldade enfrentou Michel Foucault quando, ao romper com a grande continuidade da história moderna, propôs a categoria de episteme, caracterizando-a como uma estrutura autopoética impermeável à noção de continuidade ou evolução histórica.

Como então caracterizar o tempo de passagem entre esses dois quadros históricos sem recair em categorias como transição, continuidades e permanências? De fato, isso não me parece possivel ou desejável. Mesmo Koselleck mostrou não estar disposto a abdicar de uma das conquistas mais preciosas da historiografia moderna, a saber, a idéia de que o próprio processo histórico é capaz de prover o historiador com categorias cognitivas. Vista retrospectivamente, a história do século XVIII pode ser concebida como uma transição para o moderno, embora em seu próprio momento histórico efetivo esse caminho era apenas um entre outros possiveis. 0 estudo dos conceitos para o caso brasileiro tem demonstrado que os próprios sujeitos históricos possuiam uma consciência crescente de viver em um período de transformações aceleradas, um tempo marcado pela transitoriedade.

Devemos, no entanto, diferenciar "transição" enquanto categoria da análise historiográfica - que independe da percepção dos atores e pode identificar certos fenômenos estruturais -, de transição enquanto uma sensação coeva aos sujeitos históricos em tela. A percepção de que viviam em um mundo provisório, de que algo começava a ser construído é crescentemente presente nesta conjuntura, o que seria uma das conseqüências e possibilidade estrutural da experiência moderna da história, como demonstrou Hans Ulrich Gumbrecht ao definir o que chamou de cronótopo tempo histórico. ${ }^{12}$ Portanto, para o caso brasileiro, transição pode ser usada tanto como categoria historiográfica quanto como uma descrição de certos traços da experiência vivida. Neste último caso, convêm salientar que para este recorte, poucas vezes tinha-se a consciência do ponto de chegada possivel da transição em aberto, como bem salientou Zermeño.

Um ponto possivel de divergência entre as cronologias hispano-americana e a brasileira no que se refere ao conceito de história é o momento em que a chamada "História contemporânea" adquiriu centralidade. Zermeño aponta a década de 1820 como marco, quando para o caso brasileiro ela já tinha importantes formulações desde, pelo menos, 1808, penso aqui particularmente em autores como Hipólito José da Costa, Padre Perereca, José Bonifácio, entre outros. A famosa expressão de Leibniz "o presente está prenhe de futuro" serviu de programa para uma agenda de pesquisa que procurava resolver as incertezas do porvir através da investigação sistemática da história do presente. Esse movimento contribuiu profundamente para transformar o discurso histórico em uma das mais importantes armas políticas daquele contexto de crise. Cada projeto de futuro que disputava o espaço público procurava interpretar nos eventos contemporâneos os elementos de fundamentação de suas próprias esperanças. Essa concepção de História Contemporânea legitimava-se freqüentemente nos clássicos da Antiguidade, bem como em seus modelos formais de escrita de uma história/anais. Esse modelo de historiografia só perdeu sua centralidade quando a estabilidade política e o processo de consolidação do Estado permitiram uma despolitização do discurso histórico, transformando-o em ciência "imparcial". Para esse novo modelo, a história contemporânea estava fora de questão. ${ }^{13}$ 
14

Cf. PIMENTA, João Paulo Garrido. Brasil y las revoluciones de Hispanoamérica (18081822). In ____. Brasil y las independencias de Hispanoamérica. Castellon de la Plana: Publicacions de la Universitat Jaume, 2007. p. 13-29.

\section{5}

Sobre este aspecto ver a precisa e exaustiva análise de SILVA, Ana Rosa Cloclet da. Inventando a Nação: intelectuais ilustrados e estadistas luso-brasileiros na crise do Antigo Regime Português (1750-1822). São Paulo: Hucitec, 2006. p. 108-109, entre outras.
É certamente pleno de conseqüências para nossa experiência moderna o fato de Napoleão, e não diretamente a Revolução Francesa, poder ser considerado o grande ponto de referencia, como brilhantemente destaca Zermeño. Este parece ter sido o caso no mundo luso-brasileiro. De outra forma, poderiamos dizer que nossa experiência da Revolução Francesa foi decisivamente filtrada pela expansão napoleônica. Isso talvez ajudasse a explicar a presença, muitas vezes precoces, de procedimentos "modernistas" na relação com o passado: formação de tradições, surgimento de um discurso conservador articulado com a noção de gradualismo. Algo certamente comparável com o que se processou no mundo britânico.

\section{A dinâmica dos conceitos e o sistema intelectual}

Ao destacar o periodo entre 1808 e 1823 como de grande transformação conceitual, Zermeño nos chama a atenção para um fator fundamental, a saber, a centralidade para nossa história conceitual dos movimentos politicos e sociais que deram origem à desarticulação dos impérios coloniais, generalizando uma sugestão feita por João Paulo G. Pimenta. ${ }^{14}$ Zermeño, no entanto, enfatiza o fato de as transformações políticas potencializarem as mudanças conceituais sem que houvesse uma elaboração intelectual prévia. Talvez aqui corramos o risco de tomar o intelectual como sinônimo de institucional, ou ainda reificarmos os modelos europeus de institucionalização do saber. Buscar no mundo luso-brasileiro deste periodo algum tipo de profunda reflexão teórico-abstrata, como se acredita haver no caso alemão, seria ignorar a própria concepção das funções do intelectual produzidas ao longo do reformismo ilustrado, ou seja, um homem de letras empiricista e pragmático. ${ }^{15}$ Além disso, não podemos subestimar a força da circulação conceitual no interior da república das letras e de sua capacidade de, ao possibilitar a transplantação e tradução conceitual, catalizar as transformações sócio-políticas. Portanto, para prosseguirmos na correta avaliação do fenômeno destacado por Zermeño teríamos que fazer valer a idéia de circularidade entre os conceitos e o real sugerida por Koselleck, investigando tanto o caráter próprio de funcionamento de nossos sistemas intelectuais, quanto os modos, as formas e funções das trocas conceituais.

Ainda sobre esse ponto, não creio que a importância das transformações sócio-políticas para a dinâmica conceitual seja uma particularidade do caso ibérico. No verbete "história", Koselleck ressaltou a centralidade das transformações político/sociais produzidas pela Revolução Francesa como ponto de partida para um processamento reflexivo dos conceitos modernos. Como situamos Napoleão e a experiência das independências como nosso equivalente "revolucionário", deveríamos buscar esse processamento reflexivo um pouco mais adiante, entre as décadas de 1820 e 1840: o que certamente seria verdadeiro para o caso brasileiro, tanto pela criação de espaços institucionais quanto pela ascensão das primeiras "vanguardas" estéticas, com o romantismo. 0 certo, no entanto, é que em nossa tradição não houve a mesma ênfase no tratamento teórico/sistemático. Para o caso brasileiro Antonio Candido formulou a expressão "literatura empenhada"; e Luiz Costa Lima a noção de uma estrutural dificuldade de autonomização do sistema intelectual, essas análises longe de apontar para a irrelevância da dimensão intelectual, revelam a dificuldade de separar os fenômenos intelectuais dos políticos e sociais. 


\section{6}

Gumbrecht tem chamado a atenção para o fato de que a expectativa de algum tipo de aprendizado prático com o estudo da história tem sido uma constante fundamental para a própria legitimação do campo nos últimos duzentos anos, mas que, ao mesmo tempo, tem sido cada vez mais difícil fundamentar essa promessa. Cf. GUMBRECHT, Hans Ulrich. Depois de aprender com a história In _____. Em 1926: vivendo no limite do tempo, p. 549-463 e, mais recentemente, GUMBRECHT, Hans Ulrich. Production of presence: what meaning cannor convey. Stanford: Stanford University Press, 2004. p. 118-119.

\section{7}

Essa recepção já tem uma história formada não apenas pelas pesquisas, mas pela crescente tradução de textos. Um marco inaugural foi, sem dúvida, a tradução do artigo "Uma história dos conceitos: problemas teóricos e práticos" (Estudos Históricos, Rio de Janeiro, vol. 5, n. 10, 1992, p. 134-146), feita por Manoel Luiz Salgado Guimarães. Em 1999, a Eduerj e a contraponto editaram a influente tese de doutorado de Koselleck sob o título Crítica e Crise: contribuição à patologia do mundo burguês; em 2006, também a contraponto, associação à editora da PUC-Rio, disponibilizou o mais relevante conjunto de ensaios sobre história conceitual publicado por Koselleck (Futuro Passado: contribuição à semântica dos tempos históricos). Por fim, embora essa lista não seja exaustiva, cabe referência à coletânea organizada por JASMIM, Marcelo Ganthus e FERES JÚNIOR, João. História dos conceitos: debates e perspectivas. Rio de Janeiro: Editora da Puc-Rio, 2006.

Recebido para publicação em março de 2008

\section{Historia magistra uitae}

Um dos problemas que considero mais dificeis de dimensionar na história da historiografia do XIX é o significado da permanência do topos história magistra uitae. De um lado, pode ser tratado como permanência de parâmetros clássicos do conceito de história, indicando assim certa resistência ao moderno. Como Zermeño muito bem observa, é natural que certas soluções teóricas demorem a alcançar outros estratos sociais. Por outro lado, parece-me que a expressão foi adaptada ao conceito moderno de história, sem que sua presença possa por si só ser indicativo de algum tipo de persistência do conceito clássico de história.

Em sua figuração precisa, o que sustenta a concepção ciceroniana de história é uma percepção cíclica do tempo, e, associado a isso, uma noção forte de natureza humana. A história filosófica do XVIII, mesmo deslocando as duas categorias, permaneceu ainda em seu interior - a noção de ciclos históricos não foi eliminada por completo e a razão é uma dimensão da natureza intemporal do homem - mesmo a concepção de história em Kant, por exemplo, não se emancipou por completo desses limites. Portanto, na maior parte do século XVIII, o topos história mestra da vida foi adaptado a uma história civil ainda capaz de orientar a humanidade a partir de certas lições filosóficas intemporais.

Com as filosofias da história do século XIX, cujo marco qualitativo é Hegel, a modernidade tornou-se singular e o homem já não possuía uma natureza intemporal, logo, o passado não pode dar exemplos. Ao mesmo tempo, o etapismo das filosofias da história permitiu tirar lições do passado, já que pela sua análise é possível vislumbrar o futuro, mesmo que esse já não fosse concebido em termos de repetição do passado. Assim, o topos pode ser adaptado a esse novo tipo de lição histórica: é possivel aprender com o passado, mas não imitá-lo, como é fundamental na concepção ciceroniana. 16 Em resumo, o simples uso retórico dos topoi ciceronianos não qualifica uma concepção de história como pré-moderna, pois o fundamental seria entender quais os procedimentos necessários para aprender com a história. Por isso, acredito que mesmo não havendo uma formulação crítica da historia magistra uitae, ela estava efetivamente superada, ao menos no Brasil, por volta de 1840. Acho fundamental manter uma distinção clara entre as histórias filosóficas ou civis do século XVIII e as filosofias da história do século XIX, somente com elas a experiência do tempo moderno recebeu seu tratamento teórico definitivo. Talvez por isso Koselleck só considere o Sattelzeit encerrado por volta de 1850.

As pesquisas em história dos conceitos apenas agora começam a receber atenção no contexto historiográfico brasileiro. ${ }^{17}$ Independentemente da contribuição que essa nova perspectiva pode vir a dar a uma historiografia madura como a nossa, um fator que já pode ser destacado é o retorno aos grandes problemas teóricos. 0 texto de Guillermo Zermeño é uma realização brilhante nessa direção, pois novamente nos coloca frente a um ensaio histórico no qual a pesquisa empírica e o debate teórico sistêmico colaboram sem artificialismos. 